Check for updates

Cite this: J. Mater. Chem. A, 2017, 5 , 9733

Received 20th March 2017 Accepted 13th April 2017

DOI: $10.1039 / \mathrm{c} 7 \mathrm{ta0} 2447 \mathrm{a}$

rsc.li/materials-a

\section{Hierarchically structured polymeric ionic liquids and polyvinylpyrrolidone mat-fibers fabricated by electrospinning $\dagger$}

\author{
Silvia Montolio, ${ }^{a}$ Gabriel Abarca, ${ }^{\mathrm{b}}$ Raúl Porcar, ${ }^{\mathrm{a}}$ Jairton Dupont, ${ }^{\mathrm{c}}$ \\ María Isabel Burguete, ${ }^{a}$ Eduardo García-Verdugo (iD *a and Santiago V. Luis (iD *a \\ Different polymeric ionic liquids/polyvinylpyrrolidone (PILs/PVP) fiber membranes were prepared by \\ electrospinning from the corresponding polymeric blends. Supramolecular interpolymeric interactions \\ between PILs and PVP seem to define not only the solution properties but also the final morphology and \\ performance of the mat-fibers. The fine tuning of the counter anion and the length of the alkyl chain \\ allows modulating both their hydrophilic/hydrophobic properties and their morphology. In this way, it \\ was possible to obtain materials with potential applications in different fields as highlighted by the \\ promising results obtained for oil-water separation or for the synthesis and stabilization of AuNPs.
}

\section{Introduction}

Electrospun polymer fibers are of great current interest because they allow the preparation of nanostructured materials with potential applications in different fields such as filter media, ${ }^{1}$ energy, ${ }^{2}$ drug delivery, ${ }^{3}$ nanosensors, ${ }^{4}$ tissue engineering ${ }^{5}$ or catalysis. ${ }^{6}$ Ultrafine fibers can be produced by several techniques but the use of electrospinning has been increasingly investigated. $^{7}$ It is considered as one of the most simple, efficient and versatile methods for preparing mats of micro- and nanoscaled fibers from polymer solutions. ${ }^{8}$ The nanofiber morphology and microstructure obtained can be controlled and adjusted by the experimental electrospinning parameters and by the intrinsic physico-chemical properties of the polymer or polymer mixtures used in the preparation. ${ }^{8}$ In this context, the fabrication of polymeric membranes based on a variety of blends in which each of the components provides a series of specific properties to the membrane is of increasing importance, particularly in energy related fields. ${ }^{\mathbf{9}, 10}$

Ionic liquids (ILs) are well-known materials with excellent tuneable physico-chemical properties. ${ }^{\mathbf{1 1}}$ The application of ILs to materials science has led to new scientific and technologic developments. ${ }^{\mathbf{1 2}}$ ILs have been employed as functional advanced materials, advanced media for materials production or components for preparing highly functional materials. ${ }^{13}$

\footnotetext{
${ }^{a}$ Departamento de Química Inorgánica y Orgánica, Universitat Jaume I, E-12071, Castellónde la Plana, Spain.E-mail: cepeda@uji.es; luiss@uji.es

${ }^{b}$ Laboratory of Molecular Catalysis, Institute of Chemistry, UFRGS, Avenida Bento Gonçalves, 9500, Porto Alegre 91501-970, RS, Brazil

${ }^{c}$ School of Chemistry, University Park, Nottingham, NG7 2RD, UK

$\dagger$ Electronic supplementary information (ESI) available. See DOI: $10.1039 / \mathrm{c} 7 \mathrm{ta0} 2447 \mathrm{a}$
}

Properly designed ILs can dissolve a wide spectrum of organic, organometallic and inorganic compounds and polymers. Their application in electrospinning has increased the families of materials from which fibers can be made, opening up new avenues in the preparation of fibers by this technique. Thus, for instance, ILs provide a good solvent ability for biopolymers enabling the electrospinning of recalcitrant materials like cellulose. ${ }^{\mathbf{1 4}}$ The preparation of functional hybrid materials based on blends of ILs and conventional polymers can lead to advanced systems combining the properties of polymers (e.g. mechanical strength) and ILs (e.g. high ionic conductivity, high thermal stability, or catalytic activity). ${ }^{15}$ This can also be accomplished by the design of polymeric ionic liquids (PILs). ${ }^{\mathbf{1 6}}$ The solution properties of this kind of polyelectrolytes make them electrospinnable polymers enabling the development of PIL-based membrane systems with interesting morphologies. Besides, the properties of these membranes can be easily adjusted by fine tuning the PIL structure. The surface wetting behaviour, ${ }^{17,18}$ for instance, can be greatly affected by a simple exchange of PIL anions, with anions such as $\mathrm{Cl}^{-}, \mathrm{Br}^{-}$and $\mathrm{BF}_{4}{ }^{-}$ providing hydrophilicity, and others like $\mathrm{PF}_{6}{ }^{-}$and $\mathrm{Tf}_{2} \mathrm{~N}^{-}$ impairing hydrophobicity. ${ }^{19}$ However, there are scarce examples of the formation of electrospun membranes derived from the homopolymers obtained by free radical polymerisation of the ionic liquid monomers. This is associated with the difficulty in preparing PILs with the physicochemical properties required for this purpose and the examples reported are always based on PILs having a large molecular weight but, at the same time, displaying a very large and uncontrolled polydispersity. ${ }^{\mathbf{2 0 , 2 1}}$

Here, we report on the synthesis, characterization and application of polymeric membranes prepared by electrospinning of blends of different PILs with poly(vinylpyrrolidone) (PVP). The PIL/PVP interactions define the morphology and 
properties of the obtained membranes. The fine-tuning of the counter anion and the length of the alkyl chains on the ILfragments allows modulating their hydrophobic/hydrophilic properties and the morphology of the fibers obtained. The mats obtained can be used for oil-water separation and as nanostructured supports for the synthesis and stabilization of metal nanoparticles by sputtering deposition.

\section{Experimental}

\section{Materials}

All the reagents and solvents used were commercially available and were used as received unless otherwise stated. 4-Vinylbenzyl chloride ( $p$-chloromethylstyrene, 90\%, Aldrich) was purified by passing through a column of basic aluminium oxide. 4-Cyano-4-(phenylcarbonothioylthio)pentanoic acid (CPA, >97\%, Aldrich), 4,4'-azobis(4-cyanovaleric acid) (ACVA, $>98 \%$, Aldrich), $\mathrm{N}, \mathrm{N}$-dimethylformamide (DMF, 99.5\%, Scharlab), 1-methylimidazole (99\%, Aldrich), 1-octylimidazole (98\%, Aldrich), 2-methyl tetrahydrofuran (2-Me-THF, 99\%, Acros), methanol (MeOH, 99.9\%, Scharlab), bis(trifluoromethane)sulfonimide lithium salt ( $\operatorname{LiNTf}_{2}, 99 \%$, Aldrich) and acetone HPLC (99.9\%, Scharlab) were used as received. Polyvinylpyrrolidone (PVP) had $M_{\mathrm{w}}=1300000$ and was obtained from Aldrich.

\section{Materials characterization}

The surface morphology of the electrospun films was analyzed with a scanning electron microscope (SEM) (JEOL 7001F) after platinum coating. The diameter of the fibers was measured on the basis of SEM images. IR spectroscopy was used to check intra- and inter-polymer interactions and the molecular structure of the membranes. FT-IR spectra were obtained using a spectrometer (JASCO FT/IR-6200) equipped with an ATR (MIRacle single-reflection ATR diamond/ZnSe) accessory at 4 $\mathrm{cm}^{-1}$ resolution (4000-600 $\mathrm{cm}^{-1}$ spectral range). Differential scanning calorimetry (DSC) (DSC8, Perkin Elmer) was performed in a nitrogen atmosphere at $10{ }^{\circ} \mathrm{C} \mathrm{min}^{-1}$ heating rate. Elemental analyses were obtained with a CHN Euro EA 3000 instrument. Wettability of the membranes was determined by using a static contact angle goniometer in open air (Phoenix150, Surface Electro Optics, Korea).

\section{Synthesis of poly(vinylbenzyl chloride) 2}

Compound 1 (50.0 g, $327 \mathrm{mmol})$, CPA (0.915 g, $3.27 \mathrm{mmol}$ ) and ACVA (0.275 g, $0.983 \mathrm{mmol}$ ) were dissolved in DMF (46 $\mathrm{mL}$ ) and the solution was deoxygenated with five freeze-thawcycles. Then, the mixture was heated at $120{ }^{\circ} \mathrm{C}$ for 24 hours. The polymerization was stopped by immersing the flask in liquid nitrogen. The mixture was diluted with acetone and the product was isolated by precipitation with methanol followed by further purification by two precipitations with acetone and methanol. Polymer 2 was isolated with $45 \%$ yield and a molecular weight of $6.9 \mathrm{~kg} \mathrm{~mol} \mathrm{~mol}^{-1}$ (1.5 PDI, determined by GPC).

\section{Synthesis of polymeric ionic liquids $4 a-b$}

Synthesis of 4a. 1-Methylimidazole (3a, 6.3 mL, $79.2 \mathrm{mmol})$ was added to a solution of polymer $2(6.04 \mathrm{~g}, 39.6 \mathrm{mmol})$ in 2 Me-THF $(24 \mathrm{~mL})$. The reaction was allowed to proceed at $40{ }^{\circ} \mathrm{C}$ for 2 days. The partially modified polymer precipitated during the reaction, so $\mathrm{MeOH}(40 \mathrm{~mL})$ was added to keep the polymer in solution. The polymer 4 a was finally purified by dialysis with a cellulose membrane against $\mathrm{MeOH}$ and isolated by evaporation to yield $4 a$ with $71 \%$ yield.

Synthesis of $\mathbf{4 b}$. PIL $\mathbf{4 b}$ was obtained by the same methodology described above using octylimidazole $(3 \mathbf{b}, 7.8 \mathrm{~mL}, 39.4$ $\mathrm{mmol})$ and $2(3.00 \mathrm{~g}, 19.6 \mathrm{mmol})$ in 2-Me-THF $(25 \mathrm{~mL})$ at $40{ }^{\circ} \mathrm{C}$ for 2 days. $\mathrm{MeOH}(35 \mathrm{~mL})$ was added to the reaction mixture to avoid the precipitation of the partially modified polymer. The final polymer was obtained by dialysis against $\mathrm{MeOH}$ and isolated by evaporation to yield PIL $\mathbf{4 b}$ (76\% yield).

\section{Synthesis of polymeric ionic liquids $5 \mathbf{a}-\mathbf{b}$}

Synthesis of 5a. A solution of $\operatorname{LiNTf}_{2}(3.40 \mathrm{~g}, 11.8 \mathrm{mmol})$ in acetone $(20 \mathrm{~mL})$ was added to a solution of $4 \mathrm{a}(2.50 \mathrm{~g}, 10.6$ $\mathrm{mmol}$ ) in $\mathrm{MeOH}(35 \mathrm{~mL})$. The mixture was stirred at room temperature for 24 hours. After evaporation, the residue was suspended in Mili-Q ${ }^{\circledR}$ water $(40 \mathrm{~mL})$ and extracted with EtOAc $(3 \times 30 \mathrm{~mL})$. The organic fractions were collected, dried over anhydrous $\mathrm{MgSO}_{4}$ and vacuum evaporated to afford polymer 5a (80\% yield).

Synthesis of $\mathbf{5 b}$. Polymer $\mathbf{5 b}$ was obtained by the same methodology used to obtain 5a, using a solution of $\operatorname{LiNTf}_{2}$ $(1.90 \mathrm{~g}, 6.6 \mathrm{mmol})$ in acetone $(20 \mathrm{~mL})$ and a solution of $4 \mathbf{b}$ $(2.00 \mathrm{~g}, 6.0 \mathrm{mmol})$ in $\mathrm{MeOH}(30 \mathrm{~mL}) ;(82 \%$ yield$)$.

\section{Synthesis of the polymeric ionic liquid 6 a}

Synthesis of 6a. A solution of $\mathrm{CF}_{3}\left(\mathrm{CF}_{2}\right)_{3} \mathrm{SO}_{3} \mathrm{~K}(3.70 \mathrm{~g}, 10.7$ $\mathrm{mmol})$ in Mili-Q ${ }^{\circledR} \mathrm{H}_{2} \mathrm{O}(60 \mathrm{~mL})$ was mixed with a solution of polymer $4 \mathbf{a}(2.54 \mathrm{~g}, 10.8 \mathrm{mmol})$ in $\mathrm{MeOH}(170 \mathrm{~mL})$. The mixture was stirred at room temperature for 24 hours. After evaporation, the residue was suspended in Mili-Q® water $(40 \mathrm{~mL})$ and extracted with EtOAc $(3 \times 30 \mathrm{~mL})$. The organic fractions were collected, dried over anhydrous $\mathrm{MgSO}_{4}$ and vacuum evaporated to afford polymer $\mathbf{6 a}$ ( $99 \%$ yield).

\section{Preparation and properties of electrospinning solutions}

Polymer solutions for electrospinning were prepared by mixing and sonicating, for $40 \mathrm{~min}$ at room temperature, the corresponding polymer $\mathbf{2}, \mathbf{4 a}-\mathbf{b}$ or $\mathbf{5 a}-\mathbf{b},(25 \%$ by weight) with PVP ( $9 \%$ by weight) in the appropriate solvent (DMF or $\mathrm{MeOH}$ ).

\section{Characterization of the electrospinning solutions}

Three main parameters were determined for each solution assayed. Surface tension: it was obtained by the pendant drop method by using a Phoenix-150 instrument (Surface Electro Optics, Korea). Viscosity: it was determined with a rotating viscometer (Brookfield R/S-CPS+ Rheometer, USA). Conductivity: it was measured by electrochemical impedance 
spectroscopy (broadband dielectric spectrometer NOVOCONTROL CONCEPT-80, BDS-80, Germany).

\section{Electrospinning process}

The electrospinner used in this study was a Fluidnatek LE 100.V1 (BioInicia, Spain). The polymer solutions were loaded into a plastic syringe equipped with a stainless steel needle tip (0.9 $\mathrm{mm}$ inner diameter). The tip-collector working distance was fixed at $16 \mathrm{~cm}$. The applied voltage was kept between +23 and $-13 \mathrm{kV}$ and the flow rates ranged from 1 to $2 \mathrm{~mL} \mathrm{~h}^{-1}$. The electrospun fibers were collected on aluminum foil that covered a rotating collector. All electrospinning experiments were carried out at room temperature and a relative humidity of $36 \%$. The obtained membranes were vacuum dried overnight in an oven at $50{ }^{\circ} \mathrm{C}$.

\section{Sputtering process}

A film mat of the corresponding polymeric blend $(40 \mathrm{mg})$ was placed into a Petri plate ( $3 \mathrm{~cm}$ in diameter) and degassed for $2 \mathrm{~h}$ at $298 \mathrm{~K}$ under vacuum prior to introduction into the sputter chamber. The vacuum chamber was placed under a sputtering working pressure of 3 mbar by adding an Ar flow. Au $(99.999 \%$ purity) deposition was performed in a MED 020 (Bal-Tech, CMM-UFRGS), in the sputter mode, with a discharge voltage of $345 \mathrm{~V}(40 \mathrm{~mA})$ for $120 \mathrm{~s}$. After the deposition, the chamber was vented with $\mathrm{N}_{2}$. The films were recovered and stored for their further characterization and application.

\section{TEM}

For the transmission electron microscopy (TEM) analyses, the samples were dispersed in ethanol at $25{ }^{\circ} \mathrm{C}$ and then submitted to ultrasonic agitation over $20 \mathrm{~min}$. After this, two drops of the dispersion were placed on a carbon coated copper grid. Micrographs were obtained using a JEOL JEM1200 EXII operating at an acceleration voltage of $80 \mathrm{kV}$ at $200 \mathrm{kV}$ (CMM-UFRGS). The diameters of the particles in the micrographs were measured using the software ImageJ.

\section{Ultraviolet-visible diffuse reflectance spectra}

UV-Vis spectroscopy measurements were performed in a Shimadzu UV2450 spectrophotometer (diffuse reflectance mode) using an integrated sphere accessory and a light wavelength range between 200 and $800 \mathrm{~nm}$. The band gap was estimated from the intercept of the absorption edge with the energy axis in the plot $(k / s)^{2} v s . h v$ as reported in the literature. ${ }^{22}$

\section{Results and discussion}

\section{Preparation of nano-structured PIL/PVP mats by electrospinning}

PILs $\mathbf{4 a - b}$ were prepared by chemical modification of polymer 2, which was obtained by reversible addition-fragmentation chain-transfer (RAFT) polymerization. This modification was carried out using two $\mathrm{N}$-substituted imidazoles, bearing two different $N$-alkyl groups $\left(\mathrm{R}=-\mathrm{CH}_{3}(3 \mathbf{a})\right.$ and $\mathrm{R}=-\left(\mathrm{CH}_{2}\right)_{7} \mathrm{CH}_{3}$ (3b), Scheme 1). ${ }^{23}$ Metathesis of the $\mathrm{Cl}^{-}$counter anions by the more hydrophobic $\mathrm{NTf}_{2}{ }^{-}$and $\mathrm{CF}_{3}\left(\mathrm{CF}_{2}\right)_{3} \mathrm{SO}_{3}{ }^{-}$anions led to the corresponding PILs 5a-b and 6a, respectively (Scheme 1).

Initial electrospinning attempts of a solution composed solely of PIL 4a failed to produce fibers. The obtained materials were mainly composed of beads. This can be due to the low molecular weight of the polymer precursor $2\left(6.9 \mathrm{~kg} \mathrm{~mol}^{-1}\right)$ and the associated very low viscosity of the resulting solutions. It is known that the molecular weight of the polymer is an important factor to define the resulting morphologies in this process. ${ }^{8}$

In order to overcome this problem, the blending of the PILs with an additional polymer of higher molecular weight and which could be easily electrospun was employed. Polyvinylpyrrolidone (PVP) was selected as the blending polymer. PVP is a linear biocompatible synthetic polymer able to increase the viscosity of the polymer solutions and with good electrospinnability that, additionally, is soluble in water and different organic solvents. ${ }^{24}$ Furthermore, PVP presents specific benefits related to electrospinning like its extractability and ability to act as a non-ionogenic partner for the electrospinning of an ionogenic polymer. ${ }^{25}$ Hence, PVP is widely used in the fabrication of fibers via electrospinning with various other materials that are unspinnable or hardly spinnable by acting as a polymer carrier, a partner or a guide.

Different polymer solutions were prepared by mixing polymers $2, \mathbf{4 a}-\mathbf{b}$ or $\mathbf{5 a}-\mathbf{b},(25 \% \mathrm{w})$ and PVP $(9 \% \mathrm{w})$ in the corresponding solvent. For polymer 2 and PILs $\mathbf{5 a - b}$ displaying a more hydrophobic character, DMF was used as the solvent, while $\mathrm{MeOH}$ was used for the more hydrophilic PILs $\mathbf{4 a - b}$ containing chloride and the counter anion. The use of PVP/PIL

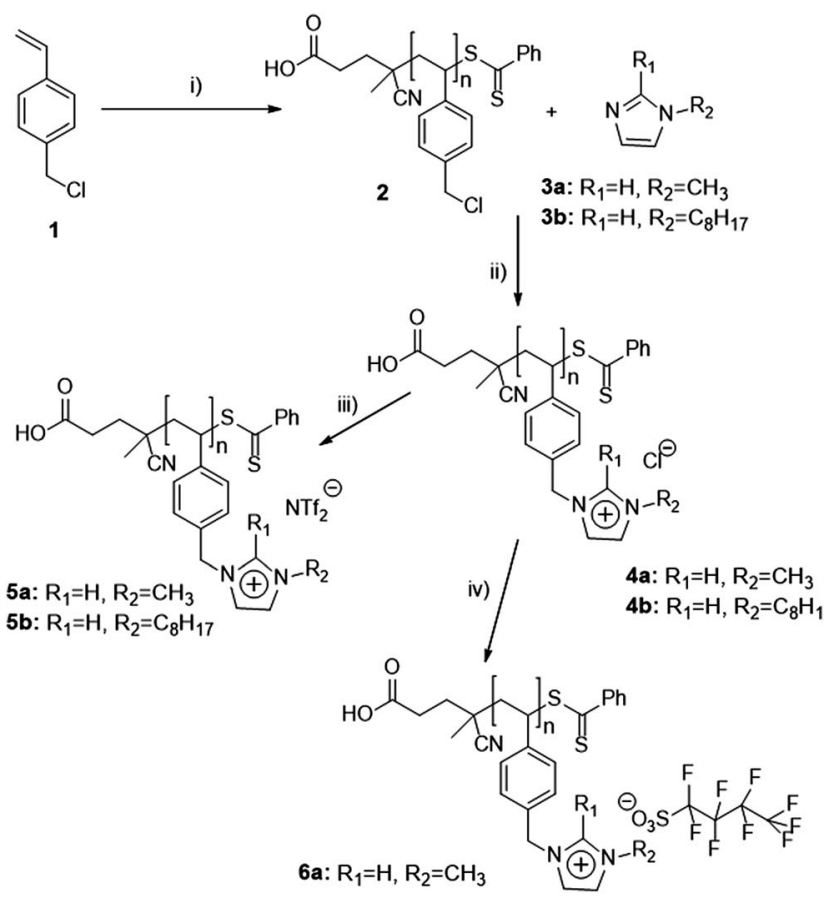

Scheme 1 Synthesis of PILs. (i) CPA, ACVA, $120^{\circ} \mathrm{C}, 24 \mathrm{~h}$ DMF. (ii) 2$\mathrm{Me}-\mathrm{THF} / \mathrm{MeOH}, 40^{\circ} \mathrm{C}, 2$ days. (iii) $\mathrm{LiNTf}_{2}, \mathrm{MeOH} /$ Acetone, r.t., 24 h. (iv) $\mathrm{CF}_{3}\left(\mathrm{CF}_{2}\right)_{3} \mathrm{SO}_{3} \mathrm{~K}, \mathrm{MeOH} / \mathrm{H}_{2} \mathrm{O}$, r.t., 24 h. 
mixtures had a significant impact on the main properties of the polymeric solutions like surface tension, viscosity and electric conductivity (Table 1).

These properties influence the electrospinnability of the corresponding polymer solutions to obtain fibers with the desired morphology. Furthermore, the $N$-alkyl substitution pattern of the imidazolium and the type of the counter ion in PILs also allow for the fine tuning of the properties of the corresponding mixtures.$^{19}$ Fiber formation is primarily governed by the viscosity of the polymer solutions and by the applied electric fields. ${ }^{26} \mathrm{~A}$ significant increase on the viscosity was observed for the polymeric mixtures in comparison with solutions solely formed by PVP. The most viscous solution was found for the mixture 5a/PVP (entry 7 Table 1 ) with a viscosity one order of magnitude greater than the one for PVP. This viscosity was more than 2.5 fold larger than the one obtained for the 2/PVP mixture corresponding to the unmodified polymer. This is consistent with the nature of the entanglements provided by the interactions between the two polymers used in the mixtures, with these interactions stronger for the polymers bearing IL-like units than for the unmodified poly( $p$-chloro-methylstyrene). Interestingly, the behaviour of viscosity as a function of the shear rate also differs for the different polymeric mixtures (Fig. S9, ESI $\dagger$ ).

On the other hand, as expected, the addition of the polymeric electrolyte increases the electric conductivity of the polymeric mixtures in comparison with the non-charged solutions by one order of magnitude. ${ }^{27}$

The solutions with one or two polymers were electrospun and collected as is schematically described in Fig. 1. The electrospinning parameters were adjusted during the electrospinning by collecting samples in situ and analysing the morphology of the materials obtained by using an optical microscope (Fig. S1, ESI $\dagger$ ). As the equipment is provided with two independent power supplies, negative voltages were applied to the collector in order to direct the electrospinning jet towards the collector.

Once the efficient electrospinning conditions were stabilised, mats composed of a dense layer of entangled fibers were obtained and collected in aluminum foil as membranes of $c a$. $20 \times 15 \mathrm{~cm}^{2}$. The mats were dried under vacuum at $50{ }^{\circ} \mathrm{C}$ and their morphology was analyzed by SEM. Fig. 2 and S2-S8 at the

Table 1 Characterisation of polymeric blends solutions

\begin{tabular}{|c|c|c|c|c|c|}
\hline Entry & Pol. mix. (solv.) & $\begin{array}{l}\text { PIL : PVP } \\
(\% \mathrm{w} / \% \mathrm{w})\end{array}$ & $\mu^{a}$ & $\gamma^{b}$ & $\sigma^{c}$ \\
\hline 1 & PVP $(\mathrm{MeOH})$ & $0: 9$ & 0.0500 & - & - \\
\hline 2 & PVP (DMF) & $0: 9$ & 0.0596 & - & - \\
\hline 3 & $\mathrm{PS}^{d}$ & - & 0.1590 & 26.9 & $2.1 \times 10^{-5}$ \\
\hline 4 & 2 : PVP (DMF) & $25: 9$ & 0.3120 & 32.6 & $1.5 \times 10^{-4}$ \\
\hline 5 & 4a : PVP (MeOH) & $25: 9$ & 0.5560 & 23.6 & $4.2 \times 10^{-3}$ \\
\hline 6 & 4b : PVP (MeOH) & $25: 9$ & 0.5360 & 32.4 & $1.3 \times 10^{-3}$ \\
\hline 7 & 5a : PVP (DMF) & $25: 9$ & 0.8430 & 32.1 & $1.1 \times 10^{-3}$ \\
\hline 8 & 5b : PVP (DMF) & $25: 9$ & 0.6030 & 28.4 & $2.7 \times 10^{-3}$ \\
\hline
\end{tabular}

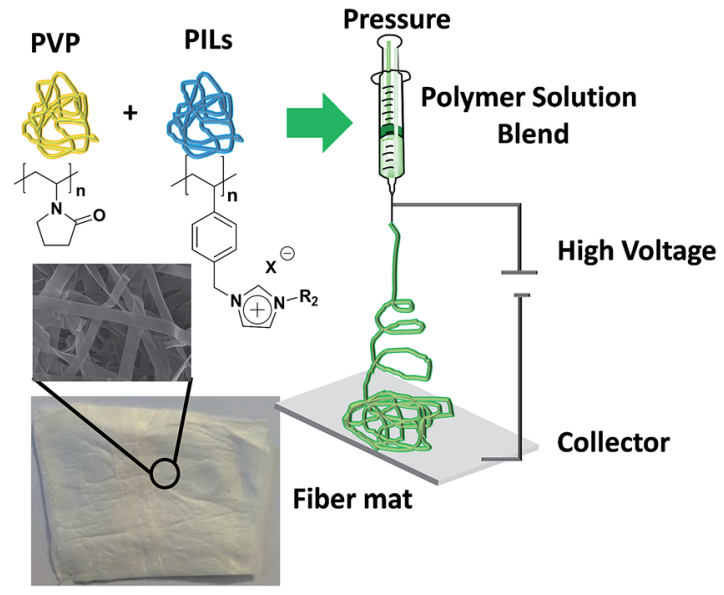

Fig. 1 Schematic diagram illustrating the formation of mats by electrospinning of a polymer blend solution of PVP $\left(M_{\mathrm{w}}=1300000 \mathrm{~g}\right.$ $\mathrm{mol}^{-1}$ ) and PILs in either DMF or $\mathrm{MeOH}$ (ca. 1/2.5 weight ratio).

$\mathrm{ESI} \uparrow$ show some representative images of the morphologies observed for the electrospun mats prepared. Table 2 summarises the main data obtained. In general, the formed mats did not show any indication of polymer phase separation at the compositions assayed. The nature of the polymeric mixtures had a strong impact on the morphology of the mats obtained. Thus, the mixture 2/PVP led to continuous, cylindrical, beadfree fibers with an average diameter of $530 \mathrm{~nm}$ (Fig. S2, ESI †). Nano-fibers with a similar morphology were also obtained for the mixtures of polymers having hydrophobic PILs, although, in these cases, the fibers were thinner $(360 \mathrm{~nm}$ and $280 \mathrm{~nm}$ for the 5a/PVP and 5b/PVP blends, respectively). This can be associated with the increase in electric conductivity for the corresponding solutions in comparison with the mixture 2/PVP (entries 7 and 8 vs. 2, Table 1) and the existence of stronger interpolymeric interactions. In an analogous way to that observed for ILs in solution, this facilitates the formation of thin and more uniform fibers in PVP. ${ }^{11,28}$

Surprisingly, polymeric mixtures containing PILs with the $\mathrm{Cl}^{-}$anion formed micro-ribbons instead of cylindrical fibers (Fig. 2a and b). In addition, the size of these micro-ribbons was in the order of micrometers rather than nanometers $(13.9 \pm 3.6$ $\mu \mathrm{m}$ and $8.8 \pm 2.5 \mu \mathrm{m}$ for the blends $4 \mathbf{a} / \mathrm{PVP}$ and $4 \mathbf{b} / \mathrm{PVP}$, respectively). A ribbon-like shape is usually attributed to the initial formation of a thin skin on the surface of a liquid jet in the early stage of the electrospinning due to the rapid evaporation of the solvent. Elimination of the remaining solvent requires its diffusion through this skin. The collapse of the resulting tube-like skin gives place to ribbon morphologies that can display a variety of cross sections. ${ }^{29,30}$ The use of $\mathrm{MeOH}$ as the solvent instead of DMF could be considered to favor this process. However, well-defined cylindrical PVP fibers were obtained under our experimental conditions for PVP in $\mathrm{MeOH}$ (10\% w, Fig. S8, ESI $\dagger$ ) in good agreement with the literature data. ${ }^{25}$ Hence, the ribbon-like shape observed for the 4a/PVP and $\mathbf{4 b} / \mathrm{PVP}$ blends should be attributed to the presence of the PIL in the polymeric mixture. An IL or PIL component will 

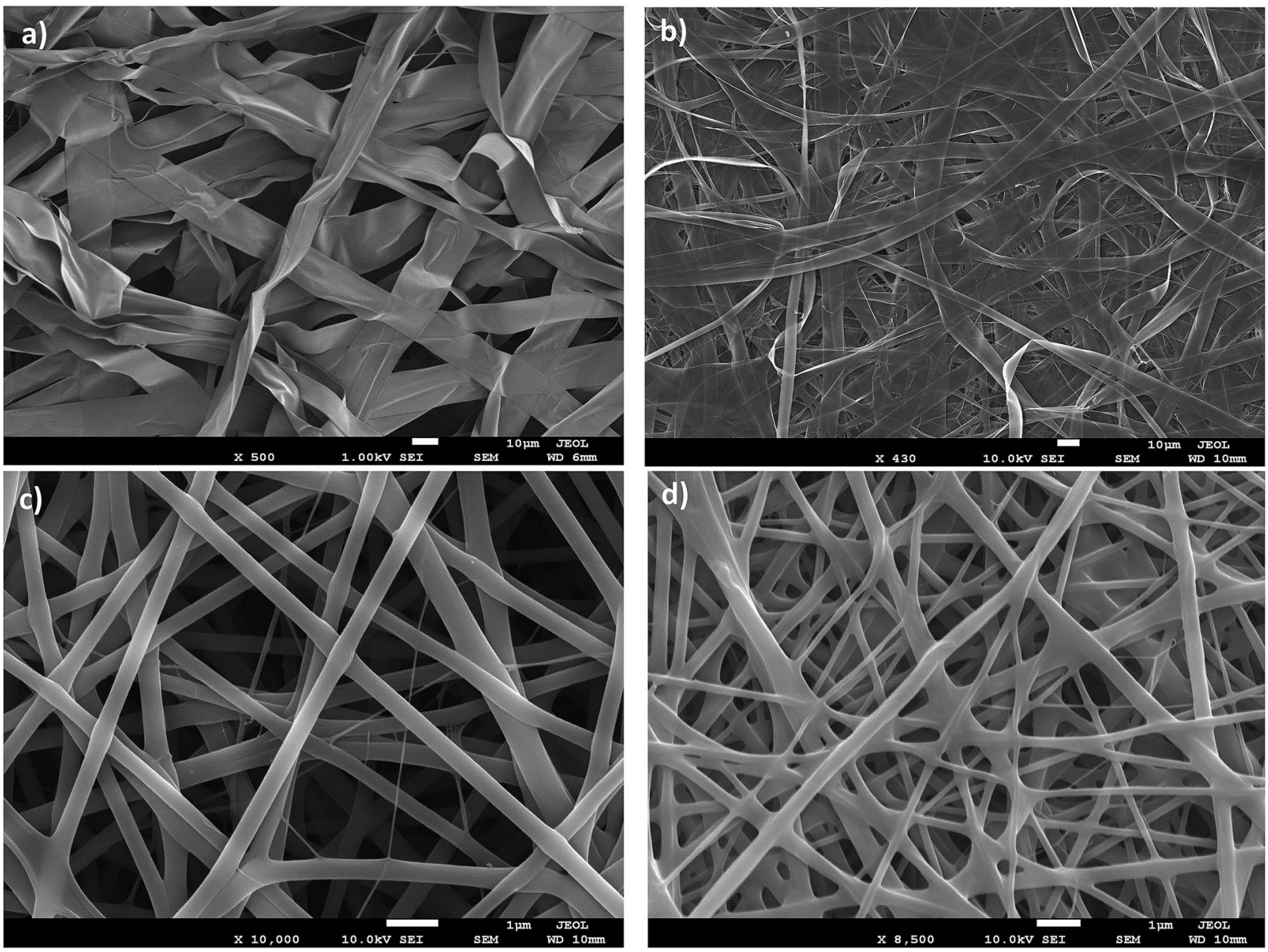

Fig. 2 SEM images for the electrospun mats formed from polymer blends 4a/PVP (a), 4b/PVP (b), 5a/PVP (c) and 5b/PVP (d).

Table 2 Electrospinning parameters used to fabricate the PIL : PVP fibers ${ }^{a}$

\begin{tabular}{|c|c|c|c|c|}
\hline Entry & Pol. mix. & Voltage (kV) & Fiber morphology & $\operatorname{Size}^{e}$ \\
\hline 1 & $2:$ PVP & $+14,-9^{b}$ & Fibers & $530 \pm 120 \mathrm{~nm}$ \\
\hline 2 & 4a : PVP & $+13,-8^{c}$ & Ribbons, thickness $0.5 \mu \mathrm{m}$ & $13.9 \pm 3.6 \mu \mathrm{m}$ \\
\hline 4 & 5a : PVP & $+21,-10^{d}$ & Fibers & $360 \pm 70 \mathrm{~nm}$ \\
\hline 5 & $5 b:$ PVP & $+21,-13^{d}$ & Fibers & $280 \pm 110 \mathrm{~nm}$ \\
\hline
\end{tabular}

produce an increase in the conductivity of the corresponding mixtures, in particular when chloride is present as the counter anion, ${ }^{27}$ and this has been shown to influence the electrospinning process, although its main effect seems to be enhancing the preparation of smooth fibers. ${ }^{31}$ Formation of electrospun flat fibers has been demonstrated to occur at high $M_{\mathrm{w}}$ and concentrations, in particular when intra- and interpolymer bonding is enforced during solvent evaporation in the electrospinning jet. ${ }^{30}$ This has also been observed for mixtures containing components that could increase inter- polymeric interactions, as is the case of a SAN (styreneacrylonitrile) copolymer in the presence of [BMIM] [Cl], ${ }^{32}$ or PVP in the presence of $\mathrm{RuNO}\left(\mathrm{NO}_{3}\right)_{3} \cdot{ }^{33} \mathrm{~A}$ strong inter-polymeric association is expected to provide a similar effect to that of high $M_{\mathrm{w}}$ polymers, and facilitate the formation of the skin on the surface of the jet leading to the ribbon morphology. Thus, the results shown in Fig. 2 suggest that inter-polymeric interactions can be stronger for the combination of PVP with PILs $\mathbf{4 a}$ and $\mathbf{4 b}$ containing $\mathrm{Cl}^{-}$as the anion, in good agreement with other experimental results that will be discussed later on. 
Another remarkable difference is that the mats derived from PILs 4a and 5a bearing IL-like units with an $N$-methyl substitution tend to give less dense entanglements than $\mathbf{4 b}$ and $\mathbf{5 b}$ displaying $\mathrm{N}$-octyl substitution and thus providing increased hydrophobic interactions.

\section{Wettability of PIL/PVP mats as a function of their composition}

The surface wettability of the mats prepared was evaluated by performing water contact angle measurements (WCA, Table 3). The wettability of a solid surface is a very important property, which is governed by both the chemical composition and the geometrical microstructure of the solid surfaces. ${ }^{34}$

The film formed by the 2/PVP blend showed a slightly hydrophobic character. It presented a WCA of $79.1^{\circ}$, similar to the one obtained for a pure PS (polystyrene) membrane obtained under analogous conditions (WCA $=78.8^{\circ}$, Table 3$)$. This result is somehow surprising as the $2 / \mathrm{PVP}$ mat is composed of ca. $9 \%$ by weight of PVP, which is a hydrophilic polymer highly soluble in water. In contrast, when a water droplet $(2 \mu \mathrm{L})$ was put in contact with the surface of the mats blended with PVP and polymers $4 \mathbf{4}-\mathbf{b}$ (PILs bearing $\mathrm{Cl}^{-}$as the anion), the water droplet immediately spreads over the film giving a formal lecture for the water contact angle of $0^{\circ}$ contact angle. This indicates, as expected, that the mats are hydrophilic, with both polymers in the blend being water soluble. However, the surface of the films derived from PILs having $\mathrm{NTf}_{2}{ }^{-}$as the counter ion showed a clear hydrophobic nature $\left(105.3^{\circ}\right.$ and $82^{\circ}$ for $5 a / P V P$ and $\mathbf{5 b} / \mathrm{PVP}$, respectively). It is worth noting that these values are larger than those obtained for PS $\left(78.8^{\circ}\right)$ and for the blend $2 /$ PVP $\left(79.1^{\circ}\right)$. These results confirm that the anion exchange in the PILs can be used to modulate the hydrophilicity/ hydrophobicity of the membrane surface. It should also be pointed out that the WCA values obtained for $\mathbf{5 a} / \mathrm{PVP}$ and $\mathbf{5 b}$ / PVP reveal a higher hydrophobic character than other materials modified with $N$-alkyl IL-units having hydrophobic counter ions (see Fig. 3). ${ }^{35-38}$

On the other hand, the previous results also put forward that surface wettability depends not only on the counter anion but also on the length of the alkyl chain. Lee et al. have shown that the wettability of Au surfaces coated with monolayers of thiolfunctionalized ILs is largely dependent on the length of $\mathrm{N}$ -

Table 3 Contact angle (CA) measurements for water and glycerol

\begin{tabular}{lllll}
\hline Entry & Method & Pol. mix. & WCA & Glycerol \\
\hline 1 & Electrospinning & $\mathbf{2}:$ PVP & 79.1 & 110 \\
2 & Electrospinning & PS $^{a}$ & 78.8 & - \\
3 & Electrospinning & $\mathbf{4 a}:$ PVP & 0 & 0 \\
4 & Electrospinning & $\mathbf{4 b}:$ PVP & 0 & 0 \\
5 & Electrospinning & $\mathbf{5 a}:$ PVP & 105.3 & 102.6 \\
6 & Casting & $\mathbf{5 a}:$ PVP & 39.8 & - \\
7 & Electrospinning & $\mathbf{5 b}:$ PVP & 82 & 124.7 \\
8 & Electrospinning & $\mathbf{6 a}:$ PVP & 65.4 & 108.1
\end{tabular}

${ }^{a}$ PS polystyrene film prepared by electrospinning a solution $30 \% \mathrm{~W}$ of PS 35000 and 5\% PS 280000 in DMF.

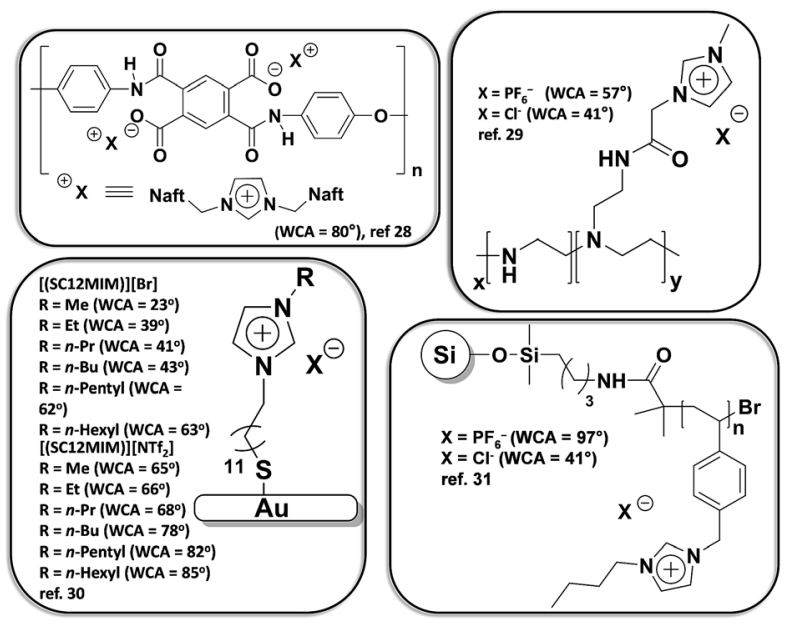

Fig. 3 WCA values reported for different materials modified with ILlike units; data taken from ref. 35-38.

alkyl chains of the imidazolium salt. ${ }^{37}$ Two different trends were claimed. For the shorter $N$-alkyl-chains (C1-C4) the nature of the counter anion controlled the surface wettability (Fig. 3). On the contrary, for long $N$-alkyl-chains $(\mathrm{C}>4)$ little effect on the WCA was observed by exchanging the anion. For these cases, it is likely that anions are embedded in the long $N$-alkyl-chains and in close contact with the imidazolium cations. Thus, the wettability is mainly related with the length of the $\mathrm{N}$-alkylchains (Fig. 3). Taking all this into account, it is noteworthy that the present films showed an opposite trend. The 5a/PVP film, with PILs bearing an $N$-methyl substitution, presented a WCA of $105^{\circ}$, while the electrospun 5b/PVP composite film bearing an octyl residue showed a smaller contact angle $\left(82^{\circ}\right.$, $23^{\circ}$ less than the 5a/PVP film).

It is also remarkable that a significant difference on the WCA was also observed between films with identical composition (5a/ PVP) but obtained either by casting or by electrospinning. The mats prepared by electrospinning led to hydrophobic surfaces with a WCA of $105.3^{\circ}$, while wettability of the film prepared by casting was larger showing a significantly smaller contact angle of $39.8^{\circ}$. The more structured material obtained by electrospinning is clearly improving the hydrophobic nature of the surface of the films.

It should be mentioned that in the case of self-assembled monolayers of long-chain fluorinated imidazolium ILs grafted via -Si-O- covalent bonds to Al surfaces, superhydrophobic materials (WCA above $160^{\circ}$ ) were obtained. ${ }^{39}$ PIL 6a bearing perfluorobutanesulfonate as the anion was prepared by a simple anion exchange from 5a. The presence of the fluorinated chain in the counter ion was expected to enhance the hydrophobic behaviour of the film formed by electrospinning the corresponding solution of 6a/PVP. Surprisingly, the resulting film displayed a smaller WCA $\left(65.4^{\circ}\right)$ being even smaller than that obtained for $2 / \mathrm{PVP}\left(79.1^{\circ}\right)$.

The SEM images of the mats obtained from a 6a/PVP mixture (Fig. 4) show a morphology displaying a combination of very thin fibers and larger ribbons. According to data obtained from 


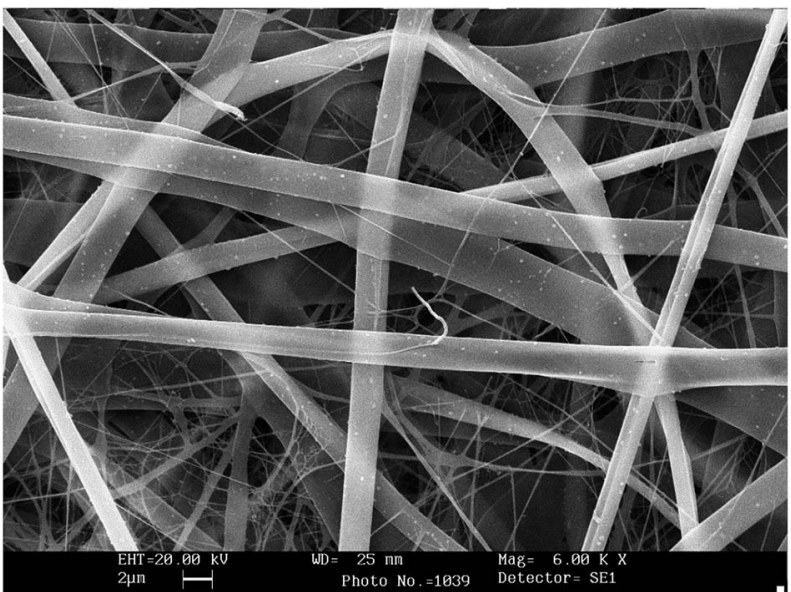

Fig. 4 SEM images for the electrospun mats formed from polymer blends $6 a / P V P$.

pure PVP mats (Fig. S8, ESI $†$ ) and from other PIL/PVP mixtures, this could correspond to the existence of some polymer segregation in which pure PVP or enriched PVP polymer assemblies are formed along with $\mathbf{6 a}$ enriched assemblies. The presence of PVP rich entities on the surface would explain the decrease in the observed WCA.

Overall, these analyses showed the influence of different structural parameters of the PILs on the self-assembly abilities leading to membranes with different morphologies and physicochemical properties.

\section{Thermal studies}

TGA is a versatile tool for analyzing the thermal properties of materials and has been used to study the interaction of PVP with ILs. ${ }^{40}$ The TGA of pure electrospun PVP fibers reveals one step decomposition at temperatures around $400{ }^{\circ} \mathrm{C}\left(T_{\mathrm{d} \text {,peak }}=\right.$ $422{ }^{\circ} \mathrm{C}$ ) in good agreement with the literature data for PVP, ${ }^{40}$ and the presence of a significant amount of water ( $c a .16 \%)$ adsorbed during the electrospinning process (Fig. S10a, ESI†). Interestingly, in the case of mats containing PVP and PILs $\mathbf{4}$ or $\mathbf{5}$ the water content observed was lower in spite of the presence of the ionic fragments associated with PILs, suggesting the existence of a strong interaction between the two polymeric phases. The membranes formed from $4 \mathbf{a} / \mathrm{PVP}$ and $\mathbf{4 b} / \mathrm{PVP}$ displayed a water content of 12.8 and $7.8 \%$ respectively, in agreement with the more hydrophobic character of PIL $\mathbf{4 b}$ associated with its longer aliphatic $N$-substituent. As expected, the lowest water content was found for mats formed with PILs bearing the $\mathrm{NTf}_{2}{ }^{-}$ anion (5a/PVP and 5b/PVP, ca. 2.5\%). Membranes containing PILs $4 \mathbf{a}$ and $\mathbf{4 b}$ with $\mathrm{Cl}^{-}$as the counter ion show a three-step decomposition. The first decomposition takes place at $T_{\mathrm{d} \text {,peak }}$ $=242{ }^{\circ} \mathrm{C}$ and $266^{\circ} \mathrm{C}$ for $4 \mathbf{a}$ and $\mathbf{4 b}$, respectively and corresponds to the nucleophilic attack of the anion on the benzylic carbon atom, with the loss of the corresponding alkyl imidazole. The second step is less well defined and takes place at a value of $c a$. $336^{\circ} \mathrm{C}$ for $T_{\mathrm{d} \text {,peak }}$. In both cases the final decomposition occurs at $T_{\mathrm{d} \text {,peak }}=435-440^{\circ} \mathrm{C}$. The thermal stability increases for mats derived from PILs 5a and $\mathbf{5 b}$ with the less nucleophilic $\mathrm{NTf}_{2}{ }^{-}$ anion, with the first decomposition mechanism essentially absent. The decomposition steps are less well defined, in particular for $5 \mathbf{a} / \mathrm{PVP}$ displaying $T_{\mathrm{d} \text {,peak }}$ values of 348 and $417^{\circ} \mathrm{C}$, while for $5 \mathbf{b} / \mathrm{PVP}$ (with a longer aliphatic tail) three steps at 324 , 328 and $412{ }^{\circ} \mathrm{C}$ are observed. The decomposition temperatures observed for the composite fibers significantly differ from those of the pure original polymers indicating that an appreciable interaction must take place in the electrospun materials. This is particularly relevant for the first decomposition step in 4a/PVP and $4 \mathbf{b} / \mathrm{PVP}$ for which $T_{\mathrm{d} \text {,peak }}$ is shifted at lower temperatures by more than $20^{\circ} \mathrm{C}$ (Fig. S10b, ESI $\dagger$ ).

The obtained mats were further investigated by differential scanning calorimetry (DSC). In a first cycle, the mats were heated to $120^{\circ} \mathrm{C}$ to eliminate adsorbed water and, after cooling, a second heating-cooling cycle was carried out from 25 to $200^{\circ} \mathrm{C}$. A third cycle was again run from 25 to $200^{\circ} \mathrm{C}$ to check the reversibility of the process. Data provided by the second DSC cycle (Fig. S11b, ESI $\dagger$ ) revealed a thermal behaviour that is clearly different from that of the individual components. Under our experimental conditions, PVP displayed a broad transition centered around $124{ }^{\circ} \mathrm{C}$ and a small $T_{\mathrm{m}}$ peak at $180{ }^{\circ} \mathrm{C}$ associated with its amorphous nature. The four selected PILs display only broad transitions in the range considered. Above $60^{\circ} \mathrm{C}, 4 \mathbf{a}$ shows a $T_{\mathrm{g}}$ of $c a$. $175^{\circ} \mathrm{C}$ that is shifted to around $132^{\circ} \mathrm{C}$ for $4 \mathbf{b}$. The presence of the less coordinating $\mathrm{NTf}_{2}{ }^{-}$anion involves the observation of a very broad $T_{\mathrm{g}}$ in the $120-130{ }^{\circ} \mathrm{C}$ range for $\mathbf{5 a}$ and the absence of any observable transition above $60^{\circ} \mathrm{C}$ for $5 \mathbf{b}$. In the case of the electrospun composites, the $\mathbf{4 a} / \mathrm{PVP}$ system displays a stronger $T_{\mathrm{m}}$ peak at $181{ }^{\circ} \mathrm{C}$ and a transition at $137^{\circ} \mathrm{C}$, suggesting an increase in the degree of order. For $4 \mathbf{b} / \mathrm{PVP}$ only one single transition is clearly observed at $141^{\circ} \mathrm{C}$. An intense peak at $126^{\circ} \mathrm{C}$ $\left(T_{\mathrm{m}}\right)$ is observed for $\mathbf{5 a} / \mathrm{PVP}$ along with a small transition at $126^{\circ} \mathrm{C}$. For the composite from the more hydrophobic PIL (5b/ PVP) two very broad transitions are present at 70-130 and 140$190^{\circ} \mathrm{C}$. Overall thermal data suggest that no phase separation is present in none of the composites and that important interactions can occur between the two polymeric components.

\section{ATR-FT-IR studies}

The presence of an amide group in PVP provides this polymer with the capacity to interact with other polymers and with different molecules through hydrogen bonding and coulombic interactions. This has been exploited for the preparation of homogeneous miscible blends with polymers displaying hydrogen donor groups like poly(vinyl alcohol), ${ }^{41}$ poly(vinylphenol), ${ }^{42}$ poly(acrylic acid), ${ }^{43}$ or the copolymer of Bisphenol A with epichlorohydrin, ${ }^{44,45}$ for the formation of blends with different drugs and other active molecules ${ }^{46}$ metal salts, ${ }^{47}$ or ILs, ${ }^{40,48}$ and for its use as a coating for a variety of NP surfaces. ${ }^{49-52}$ In all these cases, FT-IR studies, particularly involving the carbonyl stretching frequency, have provided essential data to analyze the interactions taking place. Fig. 5a shows the ATR-FT-IR regions of the $\mathrm{C}=\mathrm{O}$ bands for the different mats. The spectrum of the mat prepared with pure PVP (36\% water content under the electrospinning conditions) shows 
a)

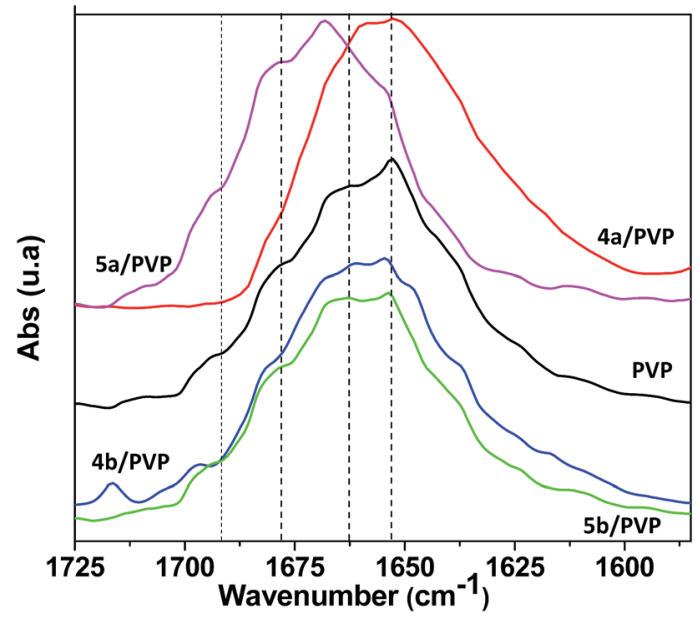

b)

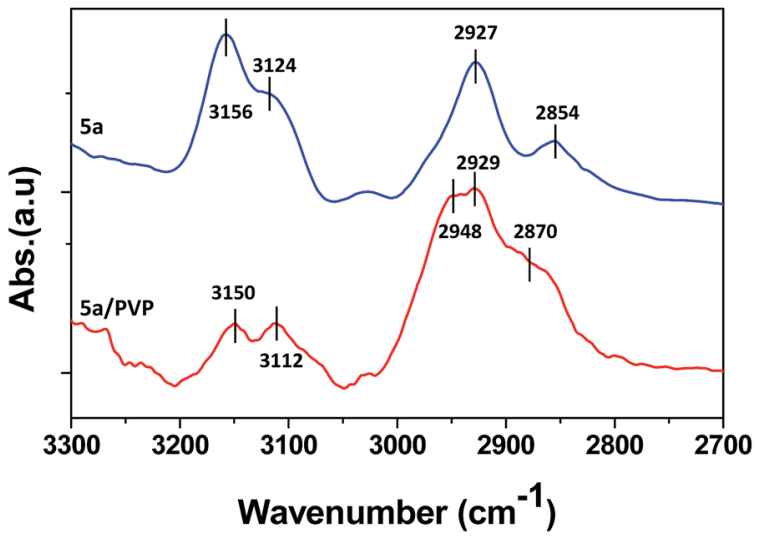

Fig. 5 Selected regions for the ATR-FT-IR spectra of (a) 4a/PVP, 4b/ PVP, PVP, 5a/PVP and 5b/PVP. (b) 5a and 5a/PVP.

a complex carbonyl band with three main components at 1678 $\mathrm{cm}^{-1}, 1663 \mathrm{~cm}^{-1}$ and $1652 \mathrm{~cm}^{-1}$. This is in good agreement with the values reported in the literature for non-hydrated, partly hydrated and strongly hydrated $\mathrm{PVP},{ }^{53}$ and similar contributions have been observed for the interaction with other hydrogen bond donors like Naproxen, ${ }^{46}$ or phenolic polymers, ${ }^{45}$ and with metal cations or MNPs. ${ }^{48-51}$ For the mat obtained with the PIL having a higher capacity of interaction, 4a/PVP, a broad red-shifted $\mathrm{C}=\mathrm{O}$ signal was observed with the predominant absorption taking place in the $1650-1665 \mathrm{~cm}^{-1}$ region. This cannot be attributed to a stronger hydration of PVP fragments as its water content is lower than that for PVP alone and indicates a strong interaction between the two polymers where coulombic interactions can occur between the oxygen of the PVP carbonyl and the cation moieties in PIL and hydrogen bonding can be established between this amide group and the acidic $\mathrm{C}-\mathrm{H}$ groups of the imidazolium cation, and including the formation of hydrogen-bonded $\mathrm{C}=\mathrm{O} \cdots$ water $\cdots \mathrm{Cl}^{-} \cdots$ imidazolium arrays. ${ }^{\mathbf{4 9}}$ The change in the anion, from $\mathrm{Cl}^{-}$to $\mathrm{NTf}_{2}{ }^{-}$, in $\mathbf{5 a}$ produces important changes in the IR spectrum of the 5a/PVP mat in the carbonyl region. An increase in the intensities at higher frequencies is observed. This can be ascribed to two different factors, the very low water content of this mat $(<3 \%)$ and the less coordinating character of the anion. In any case, the appearance of the major component at $1669 \mathrm{~cm}^{-1}$ indicates an appreciable degree of association of the amide group in PVP through electrostatic or hydrogen bonding interactions. Rather surprisingly, the substitution of the $N$-methyl substituent by the $N$-octyl group in $\mathbf{5 b}$ is accompanied by an important increase in the intensities at lower frequencies for the spectrum of the 5b/PVP mat. Thus, the presence of the long aliphatic tail on the imidazolium cation seems to favor a stronger PIL-PVP interaction. The prevalence of this structural unit in this regard is confirmed by the similar band observed in the case of the 5a/PVP mat in spite of the more coordinating anion present in $\mathbf{5 a}$.

An additional indication of the PVP-PIL interactions can be found when the characteristic peaks of the imidazolium units in PILs are compared with the ones obtained for the mats. The intense peak between 1000 and $1300 \mathrm{~cm}^{-1}$ in the spectra of PILs can be assigned to the skeletal symmetric stretching of the imidazolium ring along with components assigned to $\mathrm{CH}_{2}(\mathrm{~N})$ stretching. ${ }^{48}$ This band is found at $1161 \mathrm{~cm}^{-1}$ for $4 \mathrm{aa} / \mathrm{PVP}$ and at $1157 \mathrm{~cm}^{-1}$ for $4 \mathrm{~b} / \mathrm{PVP}$ while peaks at $1157 \mathrm{~cm}^{-1}$ and $1154 \mathrm{~cm}^{-1}$ are found for the corresponding original PILs. Finally, the bands at higher wavenumbers $\left(3300 \mathrm{~cm}^{-1}\right.$ to $\left.2700 \mathrm{~cm}^{-1}\right)$ corresponding to the symmetric and asymmetric stretching vibrations of the $\mathrm{C}(4 / 5) \mathrm{H}$ and $\mathrm{C}(2) \mathrm{H}$ groups of the imidazolium provide further information.

Fig. 5b depicts this region for PILs 5a (blue/top) and the corresponding 5a/PVP mat (red/bottom). The original PIL 5a displays clearly visible bands at $3156 \mathrm{~cm}^{-1}(\mathrm{C}(4) \mathrm{H})$ and 3124 $\mathrm{cm}^{-1}(\mathrm{C}(5) \mathrm{H})$. It is noteworthy that these bands appear at lower wavelengths $\left(3150 \mathrm{~cm}^{-1}\right.$ and $\left.3112 \mathrm{~cm}^{-1}\right)$ in the fiber mat $(5 \mathrm{a} /$ $\mathrm{PVP})$. This is characteristic of the participation of $\mathrm{C}(2) \mathrm{H}$ and $\mathrm{C}(4 /$ 5) $\mathrm{H}$ in extensive hydrogen bonding networks either directly or through $\mathrm{C}=\mathrm{O}$-water-H-C or polymer-water-polymer arrays. ${ }^{54}$

The homogeneous character of the mats was analysed by washing the mat 5a/PVP with water at r.t. (3 days). Being PVP water-soluble and $\mathbf{5 a}$ non water soluble, it could be expected that in the case of segregated or not uniform polymer mixtures, selective washing out of PVP could take place. ${ }^{55}$ This would increase the rugosity of the surface but also modify other properties like the WCA (hydrophobic/hydrophilic balance) or the chemical composition, which could be detected through ATR-FT-IR spectroscopy. In this case, the ATR-FT-IR of the washed mat showed that more than $95 \%$ of the PVP remained after this washing protocol. On the contrary, when a similar treatment was carried out for a 5a/PVP polymeric film prepared by casting with the same composition, at least $20 \%$ of the PVP was washed out. This confirms that an intimate blending is obtained through electrospinning in contrast with the situation obtained for the material prepared by casting.

\section{Application of the fiber-mats to oil/water separation and related systems}

In the search of possible applications for the materials prepared here, a series of proof-of-concept experiments were carried out to test their oil/water separation capacities. Materials composed 
of electrospun fibers with selective oil/water absorption have found promising technical applications on separation. ${ }^{56}$ Initial studies focused on the separation of a $1: 1(\mathrm{v} / \mathrm{v})$ mixture of isopropyl palmitate and water. The electrospun membrane was fixed between two glass tubes with flanged connections (Fig. S12, ESI $\dagger$ ). The liquid mixture was poured into the upper tube and the filtrate was collected on a beaker, using gravity as the only flowing force. The mat 5a/PVP displaying an excellent isopropyl palmitate wettability $\left(\mathrm{OCA}=0^{\circ}\right.$ ) and a strong hydrophobicity $\left(\mathrm{WCA}=105.3^{\circ}\right.$ ) was selected for this purpose. When a mixture $(2 \mathrm{~mL}$ ) of oil (isopropyl palmitate) and water (coloured with bromothymol blue) was used, no flow through the membrane was observed (being water the lower phase). Under strong agitation, an emulsion was formed (Fig. S12, ESI $\dagger$ ) allowing the contact of the formed oil droplets with the membrane. In this case, the oil selectively passed through the membrane and was collected in the container, while water was repelled and kept in the upper glass tube. Pure oil was obtained in the receiver vial with only very minor water content as determined by Karl-Fischer titrations. The efficiency of the separation attending the initial volumes and the permeate volume was $>99 \% .{ }^{57}$ Only traces of oil $(<0.5 \mathrm{~mol} \%)$ were detected in the upper phase at the end of the experiment as determined by NMR in DMSO- $d_{6}$. The oil flux of the membrane was obtained by calculating the permeation volume per unit time from the valid area. The membrane 5a/PVP exhibited an oil flux of $17 \mathrm{~L}$ $\mathrm{h}^{-1} \mathrm{~m}^{-2}$. These results demonstrate the potential of this kind of membranes for oil/water separations.

Polymeric materials modified with IL-like units are suitable supports for the immobilization of enzymes (e.g. lipases). ${ }^{58}$ These bioactive materials are excellent catalysts, for instance, for biodiesel synthesis. Thus, the use of electrospun mats in a similar process can be foreseen. Two approaches can be considered, one combines a catalytic phase with the membrane as the separation unit and second one involves supporting the biocatalyst in the same membrane, integrating in a single unit material transformation and separation processes. The separation of the glycerol side product from FAMES is the bottleneck in many processes for biodiesel synthesis. With this idea in mind, the contact angle for glycerol was evaluated for the different membranes (Table 3). The mat formed by $5 \mathbf{b} / \mathrm{PVP}$ showed the larger CA $\left(124.7^{\circ}\right)$, while the other hydrophobic mats presented a slightly smaller CA $\left(110^{\circ}\right.$ for $2 / \mathrm{PVP}, 102.6^{\circ}$ for 5a/PVP and $108.1^{\circ}$ for 6a/PVP). As expected, the hydrophilic membranes were wetted by glycerol (4a/PVP and $4 \mathbf{b} / \mathrm{PVP}, \mathrm{CA}=$ $0^{\circ}$ ). Thus, the membranes showed, in principle, the adequate features to facilitate the separation of biodiesel/water/glycerol mixtures (3/3/1 molar ratio). The mat 5a/PVP was selected to assay this separation as it provided good wettability by the oil while being incompatible with both water and glycerol. The oil phase (isopropyl palmitate) was easily separated from the mixture water/glycerol with a recovery of oil and glycerol of $>98 \%$ by volume. The ${ }^{1} \mathrm{H}-\mathrm{NMR}$ (DMSO- $d_{6}$ ) spectra of the oil phase obtained showed the absence of glycerol as no detectable signals at 3.4-3.8 ppm, characteristic for glycerol, were observed in the spectra. On the other hand, the analysis of the aqueous phase showed the presence of glycerol as a major component.
The analysis of the signals at $2.27,1.87,1.58,1.27,1.23$ and 0.89 assignable to isopropyl palmitate revealed the presence of minor amounts of oil in the glycerol/water phase (ca. $2.0-2.5 \%$ mol).

\section{Application of the fiber-mats as supports of MNPs}

Both bulk ILs and related polymeric materials have been used for the synthesis and stabilisation of metal nanoparticles MNPs. ${ }^{59}$ Among the different methods for the synthesis of MNPs in ILs, ${ }^{\mathbf{6 0}}$ the sputtering-deposition techniques, where gold atoms, knocked out from a gold target cathode by the argon ions, are deposited on an IL, has been revealed as an interesting alternative for the synthesis of soluble MNPs.

Generally, sputter deposition is a very clean synthesis method, because it does not introduce other chemical species. The nanoparticles prepared by this method have been found to be very stable, even in the absence of stabilizing agents, with clean surfaces, being obtained under mild conditions with an easy control of their size and shape by appropriate tuning of the sputtering conditions. ${ }^{61,62}$

In this vein, the nanostructured films based on PILs, here obtained by electrospinning, were evaluated for the preparation of mats of AuNPs-PILs. Sputter deposition of Au onto the mats was carried out for $120 \mathrm{~s}$ with a discharge voltage of $345 \mathrm{~V}$ (40 $\mathrm{mA}$ ) and a working pressure of 3 mbar generated by an Ar flow. After deposition, the chamber was vented with $\mathrm{N}_{2}$. After sputtering deposition, the films were recovered and further characterized. The change of their colour to purple was the initial indication of the deposition of the gold onto the film surface.

The morphology and composition of the films, after Au sputtering, were studied by SEM and EDX analyses. Thus, the surface composition obtained by EDX analyses showed the presence of gold in all mats, confirming successful modification. Regarding the morphology, the film without IL-like units, composed of the mixture 2/PVP, showed similar continuous, cylindrical, bead-free fibers than the initial material. The mesh of this film had also a similar degree of porosity than the original one (Fig. S2 vs. S13†). However, the average diameter size of fibers was slightly larger (740 vs. $530 \mathrm{~nm}$ ).

A similar trend was also found for the gold modified mats (5b/PVP) obtained by the blend of PVP and a hydrophobic PIL (5b). Accordingly, the fibers preserved, after modification, the original cylindrical morphology and porosity and again an increase in the fiber diameter size was detected $(635 v s .380 \mathrm{~nm}$, Fig. $6 \mathrm{~b} v s$. 2c). The larger increase observed in this case can be attributed to the more important interactions present between the AuNPs and the functionalized polymeric chains forming the mat as both IL-like and pyrrolidone side chain units can interact and stabilize AuNPs.

The mats obtained with PILs containing the $\mathrm{Cl}^{-}$anion (4a/ PVP and 4b/PVP) showed, after modification, an important change in their morphology. The SEM pictures revealed an almost complete loss of porosity for these two fiber mats (Fig. 6a vs. $2 \mathrm{a}$ and $\mathrm{S} 5$ vs. $\mathrm{S} 15 \dagger)$. The original structure formed by entangled micro-ribbons before modification suffered, upon the gold sputtering, a collapse of the porosity, probably due to 

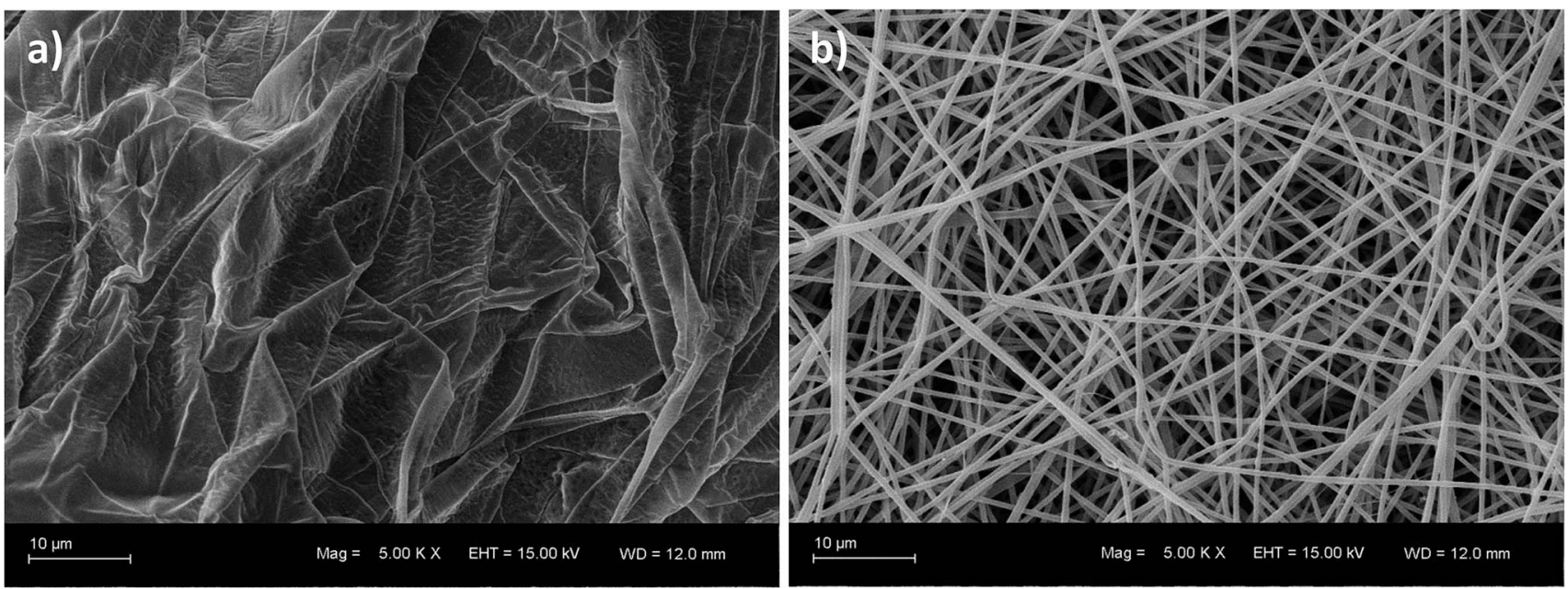

Fig. 6 SEM images for the electrospun mats formed from polymer blends 4a/PVP after sputtering (a), 5a/PVP after sputtering (b).

a strong increase in the interactions, as considered above, between the functionalized polymer and the gold nanoparticles leading to a crosslinking of the fibers. These results highlight again the close relationship between the nature of the PILs and the morphology of the materials obtained opening up the opportunity to fine tune their morphology by changing the PIL nature.

The size distribution of the formed AuNPs was obtained by TEM. Films were dispersed in ethanol at $25{ }^{\circ} \mathrm{C}$ and then subjected to ultrasonic agitation for over $20 \mathrm{~min}$. After this, two drops of the dispersion were placed on a carbon coated copper grid to be analyzed by TEM. Table 4 summarizes the sizes obtained using this methodology (micrographs in Fig. S13-S16, ESI $\dagger$ ). Variations in the NP size between the different gold modified mats were observed. Thus, the average size distribution of the smaller AuNPs was obtained for the 2/PVP mat composed of $c a$. $9 \%$ by weight of PVP $(4.11 \pm 1.02)$. PVP is well known as a polymeric nanoparticle stabiliser. For the films bearing a polymer functionalized with IL-units, the smaller AuNPs were obtained for $\mathbf{5 a} / \mathrm{PVP}$ providing an average size of $6.96 \pm 5.2 \mathrm{~nm}$.

The AuNPs obtained for the other PIL mats assayed varied slightly depending of the composition of the film. Thus, the change, in the $N$-substitution of the PIL, substituting the methyl group for a larger hydrophobic alkyl-chain led to an increase in size of the gold nanoparticles $(9.40 \pm 3.7 \mathrm{~nm}$ for $4 \mathbf{b} / \mathrm{PVP} v s .7 .55$ $\pm 2.1 \mathrm{~nm}$ for $4 \mathrm{a} / \mathrm{PVP}$ ). In the same way, for the mats containing

Table 4 Characterization of the polymeric mats after Au-sputtering

\begin{tabular}{lllll}
\hline Entry & Pol. mix. & AuNPs $^{a}(\mathrm{~nm})$ & Fiber morphology & Size $^{b}$ \\
\hline 1 & 2 : PVP & $4.11 \pm 1.02$ & Fibers & $740 \pm 109 \mathrm{~nm}$ \\
2 & 4a : PVP & $7.55 \pm 2.1$ & Collapsed ribbons & - \\
3 & 4b : PVP & $9.40 \pm 3.7$ & Collapsed ribbons & - \\
5 & 5a : PVP & $6.96 \pm 5.2$ & Fibers & $635 \pm 120 \mathrm{~nm}$
\end{tabular}

${ }^{a}$ Size determined by TEM analysis. ${ }^{b}$ Determined by SEM.
PILs bearing $\mathrm{Cl}^{-}$as the counter anion larger particles were always detected. The surface composition of the mats seemed to be the key factor in controlling the size of the AuNPs contributing both the polymeric framework itself and the IL-like moieties to the nucleation and stabilization of the gold nanoparticles. Indeed, a similar behaviour was observed in neat ILs and hybrid IL/silica materials in which the nature of the anion and the strength of the ionic pair play a major role on the size of the NPs produced by sputtering deposition. ${ }^{63}$

The band gap of the AuNPs supported onto the nanostructured film 5a/PVP was estimated by diffuse UV-Vis spectra, using the ratio of absorption to scattering $(k / s)^{2}$ from the diffuse reflection spectra and applying the Kubelka-Munk equations (Fig. S17 $\dagger$ ). ${ }^{64,65}$ The calculated value was $2.42 \mathrm{eV}(513 \mathrm{~nm}) .{ }^{66}$ This result is in agreement with the size of the AuNPs measured by TEM $(6.96 \pm 5.2 \mathrm{~nm})$ and similar to those obtained for related polymeric composites obtained by reduction with aqueous $\mathrm{NaBH}_{4} \cdot{ }^{67}$

This preliminary study suggests that by the appropriate selection of the structural parameters of the PIL mats such as the fiber morphology and nature of IL-like groups (cation and anion), AuNP-mat composites with tunable AuNP size distributions can be obtained by simple gold sputtering deposition. These type of materials can have a wide range of potential applications as catalysts, luminescent probes in biological labeling or in chemical sensing.

\section{Conclusions}

Altogether, the experimental evidence obtained in this work suggests that PILs and PVP are able to undergo strong supramolecular interpolymeric interactions between complementary structural elements directly or mediated by water molecules. Hydrogen bonding and electrostatic and hydrophobic interactions can be involved, providing homogeneous polymeric blends that favor their electrospinning in comparison with pure PILs. ${ }^{68}$ Indeed, it has been reported that by the enhancement of these interactions low molecular weight polymers or even 
nonpolymeric species can be electrospun. ${ }^{69,70}$ The differences observed, over those of the systems containing just one individual component, for the solutions containing PILs and PVP (e.g. increase in viscosity, conductivity, etc.) and for the morphology and performance of the final fibers can be related with the nature of these supramolecular interactions. Thus, the overall properties of the mats obtained can be easily tuned not only through a proper design of the electrospinning parameters, but through appropriate changes in the molecular vectors of the imidazolium fragments present in PILs, i.e. $\mathrm{N}$-substitution patterns and the nature of the counter anion. The preliminary experiments presented here reveal that this approach allows for the preparation of materials with a high potential for important applications in a broad range of currently relevant fields.

\section{Acknowledgements}

Financial support by GV (PROMETEO/2016/071) MINECO (CTQ2015-68429-R) and Pla de Promoció de la Investigació de la Universitat Jaume I (P1-1B2013-37) is acknowledged. S. M. (FPU AP2012-0667) thanks MINECO for personal funding. The cooperation of the SCIC of the UJI for instrumental analyses is acknowledged.

\section{Notes and references}

1 Q. Ma, H. Cheng, A. G. Fane, R. Wang and H. Zhang, Small, 2016, 12, 2186-2202.

2 S. Cavaliere, S. Subianto, I. Savych, D. J. Jones and J. Rozière, Energy Environ. Sci., 2011, 4, 4761-4785.

3 I. Sebe, P. Szabó, B. Kállai-Szabó and R. Zelkó, Int. J. Pharm., 2015, 494, 516-530.

4 A. MacagnanoE. ZampettiE. KnyElectrospinning for High Performance Sensors, Springer International Publishing, Switzerland, 2015.

5 Q. P. Pham, U. Sharma and A. G. Mikos, Tissue Eng., 2006, 12, 1197-1211.

6 Z. M. Huang, Y. Z. Zhang, M. Kotaki and S. Ramakrishna, Compos. Sci. Technol., 2003, 63, 2223-2253.

7 A. Greiner and J. H. Wendorff, Angew. Chem., Int. Ed., 2007, 46, 5670-5703; G. R. Mitchell, Electrospinning: Principles, Practice and Possibilities, RSC, Cambridge, 2015.

8 C. J. Angammana and S. H. Jayaram, Part. Sci. Technol., 2016, 34, 72-82.

9 Q. F. Wang, Y. Yu, J. Ma, N. Zhang, J. J. Zhang, Z. H. Liu and G. L. Cui, J. Power Sources, 2016, 327, 196-203; P. Hu, J. C. Chai, Y. L. Duan, Z. H. Liu, G. L. Cui and L. Q. Chen, J. Mater. Chem. A, 2016, 4, 10070-10083; W. Jiang, Z. H. Liu, Q. S. Kong, J. H. Yao, C. J. Zhang, P. X. Han and G. L. Cui, Solid State Ionics, 2013, 232, 44-48; L. Zhang, Z. H. Liu, G. L. Cui and L. Q. Chen, Prog. Polym. Sci., 2015, 43, 136-164.

10 J. L. Reyes-Rodriguez, O. Solorza-Feria, A. Garcia-Bernabe, E. Gimenez, O. Sahuquillo and V. Compan, RSC Adv., 2016, 6, 6986-6999; S. Molla and V. Compan, J. Membr. Sci.,
2015, 492, 123-136; S. Molla and V. Compan, J. Membr. Sci., 2011, 372, 191-200.

11 P. Wasserscheid and T. Welton, Ionic Liquids in Synthesis, Wiley-VCH, Verlag GmbH \& Co. KGaA, Weinheim, Germany, 2008, vol. 1.

12 T. Torimoto, T. Tsuda, K. Okazaki and S. Kuwabata, Adv. Mater., 2010, 22, 196-221.

13 D. Mecerreyes, Applications of Ionic Liquids in Polymer Science and Technology, Springer International Publishing, Switzerland, 2015.

14 L. Meli, J. Miao, J. S. Dordick and R. J. Linhardt, Green Chem., 2010, 12, 1883-1892.

15 A. Taubert, Eur. J. Inorg. Chem., 2015, 1148-1159.

16 L. C. Tomé, D. Mecerreyes, L. P. N. Rebelo, C. S. R. Freire and I. M. Marrucho, J. Mater. Chem. A, 2014, 2, 5631-5639.

17 B. Xin and J. Hao, Chem. Soc. Rev., 2010, 39, 769-782.

18 W. Jia, Y. Wu, J. Huang, Q. An, D. Xu, Y. Wu, F. Li and G. Li, J. Mater. Chem., 2010, 20, 8617-8623.

19 V. Sans, N. Karbass, M. I. Burguete, V. Compañ, E. GarcíaVerdugo, S. V. Luis and M. Pawlak, Chem.-Eur. J., 2011, 17, 1894-1906.

20 H. Chen and Y. A. Elabd, Macromolecules, 2009, 42, 33683373.

21 J. Yuan, A. García, J. Reinacher, C. Giordano, J. Janek and M. Antonietti, Polym. Chem., 2011, 2, 1654-1657.

22 V. Derstroff, J. Ensling, V. Ksenofontov, P. Gütlich and W. Tremel, Z. Phys. Chem., 2002, 628, 1346-1354; V. Džimbegmalčić, Ž. Barbarić-mikočević and K. Itrić, Techeniya Zhidk. Gazov, 2011, 18, 191-196; V. deSouza, J. Scholten, D. E. Weibel, D. Eberhardt, D. L. Baptista, S. R. Teixeira and J. Dupont, J. Mater. Chem. A, 2016, 4, 7469-7475.

23 E. Karjalainen, D. F. Izquierdo, V. Martí-Centelles, S. V. Luis, H. Tenhu and E. García-Verdugo, Polym. Chem., 2014, 5, 1437-1446; S. Montolio, L. Gonzalez, B. Altava, H. Tenhu, M. I. Burguete, E. Garcia-Verdugo and S. V. Luis, Chem. Commun., 2014, 50, 10683-10686.

24 J. Xie, H. Mao, D. G. Yu, G. R. Williams and M. Jin, Fibers Polym., 2014, 15, 78-83.

25 S. Chuangchote, T. Sagawa and S. Yoshikawa, J. Appl. Polym. Sci., 2009, 114, 2777-2791.

26 D. G. Yu, C. Branford-White, K. White, N. P. Chatterton, L. M. Zhu, L. Y. Huang and B. Wang, eXPRESS Polym. Lett., 2011, 5, 732-741.

27 M. Díaz, A. Ortiz, M. Isik, D. Mecerreyes and I. Ortiz, Int. J. Hydrogen Energy, 2015, 40, 11294-11302; B. Altava, V. Compañ, A. Adrio, L. F. del Castillo, S. Mollá, M. I. Burguete, E. García-Verdugo and S. V. Luis, Polymer, 2015, 72, 69-81.

28 D.-G. Yu, K. White, J.-H. Yang, X. Wang, W. Quian and Y. Li, Mater. Lett., 2012, 67, 78-80.

29 S. Koombhongse, W. Liu and D. H. Reneker, J. Polym. Sci., Part B: Polym. Phys., 2001, 39, 2598-2606.

30 A. Koski, K. Yim and S. Shivkumar, Mater. Lett., 2004, 58, 493-497.

31 C. Wang, C.-H. Hsu and J.-H. Lin, Macromolecules, 2006, 39, 7662-7672; D. Li and Y. Shia, Adv. Mater., 2004, 16, 11511170. 
32 V. Gudkova, A. Krumme, T. Märtson, M. Rikko, E. Tarassova and M. Viirsalu, J. Electrost., 2014, 72, 433-436.

33 M. Ristic, M. Marcius, Z. Petrovic, M. Ivanda and S. Music, Mater. Lett., 2015, 156, 142-145.

34 Y. Dong, J. Li, L. Shi, X. Wang, Z. Guo and W. Liu, Chem. Commun., 2014, 50, 5586-5589.

35 Y. Zhao, M. Li and Q. Lu, Langmuir, 2008, 24, 3937-3943.

36 Y. Shen, Y. Zhang, Q. Zhang, L. Niu, T. You and A. Ivask, Chem. Commun., 2005, 33, 4193-4195.

37 B. S. Lee and S. Lee, Bull. Korean Chem. Soc., 2004, 25, 15311536; B. S. Lee, Y. S. Chi, J. K. Lee, I. S. Choi, C. E. Song, S. K. Namgoong and S. Lee, J. Am. Chem. Soc., 2004, 126, 480-481.

38 X. He, W. Yang and X. Pei, Macromolecules, 2008, 41, 46154621.

39 B. Xin and J. Hao, $R S C A d v .$, 2012, 2, 5141-5146.

40 A. L. Saroj, R. K. Singh and S. Chandra, Mater. Sci. Eng., B, 2013, 178, 231-238.

41 Z.-H. Ping, Q. T. Nguyen and J. Neel, Macromol. Chem., 1989, 190, 437-448.

42 E. J. Moskala, D. F. Varnell and M. M. Coleman, Polymer, 1985, 26, 228-234.

43 M. A. Moharram and M. G. Khafagi, J. Appl. Polym. Sci., 2007, 105, 1888-1893.

44 A. Martinez de Ilarduya, J. J. Iruin and M. J. FernandezBerridi, Macromolecules, 1995, 28, 3707-3712.

45 Y. Hu, H. R. Motzer, A. M. Etxeberria, M. J. FernandezBerridi, J. J. Iruin, P. C. Painter and M. M. Coleman, Macromol. Chem. Phys., 2000, 201, 705-714.

46 A. Paudel, E. Nies and G. Van den Mooter, Mol. Pharmaceutics, 2012, 9, 3301-3317; J. Xie, H. Mao, D.-G. Yu, G. R. Williams and M. Jin, Fibers Polym., 2014, 15, 78-83.

47 M. Ravi, Y. Pavani, K. Kiran Kumar, S. Bhavani, A. K. Sharma and V. V. R. Narasimha Rao, Mater. Chem. Phys., 2011, 130, 442-448.

48 I. Bahadur, M. K. Momin, N. A. Koorbanally, M. Sattari, E. E. Ebenso, L. M. Katata-Seru, S. Singh and D. Ramjugernath, J. Mol. Liq., 2016, 213, 13-16.

49 A. L. Saroj, R. K. Singh and S. Chandra, J. Phys. Chem. Solids, 2014, 75, 849-857; Y. Borodko, S. E. Habas, M. Koebel, P. Yang, H. Frei and G. A. Somorjai, J. Phys. Chem. B, 2006, 110, 23052-23059.

50 H. Liu, B. Zhang, H. Shi, Y. Tang, K. Jiao and X. Fu, J. Mater. Chem., 2008, 18, 2573-2580.

51 Y. Zhang, J.-Y. Liu, S. Ma, Y.-J. Zhang, X. Zhao, X.-D. Zhang and Z.-D. Zhang, J. Mater. Sci, Mater. Med., 2010, 21, 12051210.

52 K. M. Koczkur, S. Mourdikoudis, L. Plavarapu and S. E. Skrabalak, Dalton Trans., 2015, 44, 17883-17905.
53 L. S. Taylor, F. W. Langkilde and G. Zografi, J. Pharm. Sci., 2001, 90, 888-901; N. Tanaka, K. Ito and H. Kitano, Macromol. Chem. Phys., 1994, 195, 3369-3380.

54 T. Koddermann, C. Wertz, A. Heintz and R. Ludwig, ChemPhysChem, 2006, 7, 1944-1949.

55 M. Bognitzki, T. Frese, M. Steinhart, A. Greiner, J. H. Wendorff, A. Schaper and M. Hellwig, Polym. Eng. Sci., 2001, 41, 982-989.

56 W. Ma, Q. Zhang, D. Hua, R. Xiong, J. Zhao, W. Rao, S. Huang, X. Zhan, F. Chen and C. Huang, RSC Adv., 2016, 6, 12868-12884.

57 M. A. Gondal, M. S. Sadullah, M. A. Dastageer, G. H. McKinley, D. Panchanathan and K. K. Varanasi, ACS Appl. Mater. Interfaces, 2014, 6, 13422-13429.

58 P. Lozano, E. Garcia-Verdugo, J. M. Bernal, D. I. Izquierdo, M. I. Burguete, G. Sánchez-Gómez and S. V. Luis, ChemSusChem, 2012, 5, 790-798.

59 K. Manojkumar, A. Sivaramakrishna and K. Vijayakrishna, J. Nanopart. Res., 2016, 18, 103.

60 K. Richter, P. S. Campbell, T. Baecker, A. Schimitzek, D. Yaprak and A.-V. Mudring, Phys. Status Solidi B, 2013, 250, 1152-1164.

61 H. Wender, R. V. Gonçalves, A. F. Feil, P. Migowski, F. S. Poletto, A. R. Pohlmann, J. Dupont and S. R. Teixeira, J. Phys. Chem. C, 2011, 115, 16362-16367.

62 H. Wender, P. Migowski, A. F. Feil, S. R. Teixeira and J. Dupont, Coord. Chem. Rev., 2013, 257, 2468-2483.

63 L. Luza, C. P. Rambor, A. Gual, F. Bernardi, J. B. Domingos, T. Grehl, P. Brüner and J. Dupont, ACS Catal., 2016, 6, 64786486; H. Wender, L. F. de Oliveira, P. Migowski, A. F. Feil, E. Lissner, M. H. G. Prechtl, S. R. Teixeira and J. Dupont, J. Phys. Chem. C, 2010, 114, 11764-11768.

64 S. Khan, M. J. M. Zapata, D. L. Baptista, R. V. Gonçalves, J. A. Fernandes, J. Dupont, M. J. L. Santos and S. R. Teixeira, J. Phys. Chem. C, 2015, 119, 19906-19914.

65 G. Kovács, Z. Pap, C. Coteţ, V. Coşoveanu, L. Baia and V. Danciu, Materials, 2015, 8, 1059-1073.

66 S. Link and M. A. El-Sayed, J. Phys. Chem. B, 1999, 103, 42124217.

67 M. I. Burguete, E. García-Verdugo, S. V. Luis and J. A. Restrepo, Phys. Chem. Chem. Phys., 2011, 13, 1483114838.

68 X. Wang, C. Pellerin and C. G. Bazuin, Macromolecules, 2016, 49, 891-899.

69 A. Celebioglu and T. Uyar, Chem. Commun., 2010, 46, 69036905.

70 D. Hermida-Merino, M. Belal, B. W. Greenland, P. Woodward, A. T. Slark, F. J. Davis, G. R. Mitchell, I. W. Hamley and W. Hayes, Eur. Polym. J., 2012, 48, 12491255. 